\title{
Implantation of the pull production system in a company of manufacture of paints and varnishes
}

\author{
Adriana Chagas Borges'; Edilson Marques Magalhães ${ }^{2 ;}$ Rosimeire Freires Pereira Oliveira $^{3}$
}

\begin{abstract}
1,2Programa de Pós-Graduação em Engenharia de Processos do Instituto de Tecnologia da Universidade Federal do Pará (PPGEP-ITECUFPA). Rua Augusto Corrêa, 1. Guamá, Belém - PARÁ - Brasil. CEP: 66075-110. Caixa Postal479. PABX: +55 91 32017000.

${ }^{3}$ Universidade Estácio de Sá. Avenida Djalma Batista, No 122. Bairro Chapada. Manaus - Amazonas - Brasil CEP:69050-010. +55 92 3303-0230.
\end{abstract}

E-mail: adrianachagaspe@yahoo.com.br,magalhes@ufpa.br, rosimeirefpol@yahoo.com.br

Received: December $9^{\text {th }}, 2016$

Accepted: January $10^{\text {th }}, 2017$

Published: March 30 1 th 2017

Copyright $(2016$ by authors and Institute of Technology Galileo of Amazon (ITEGAM) This work is licensed under the Creative Commons Attribution International License (CC BY 4.0).

http://creativecommons.org/licenses/by/4.0/ (c) (i) (3) Open Acees:

\begin{abstract}
There are many companies that seek to implement the Japanese management philosophy, known as lean manufacturing, and its principles, in order to achieve better results from the reduction of waste. In what company should you map all your processes, identifying and eliminating steps that do not add value to the customer, making it the big focus. One of the main wastes is the unnecessary stock, which ends up causing great losses, as it implies maintenance and storage costs. As well as risk of deterioration losses or items become obsolete, and yet stocks do not guarantee good customer service. The methodology used was the bibliographical survey, questionnaire application, interview, direct observation and data collection through technical visits, developed on a case study basis, in addition to the analysis of the results. In this study, the results showed that the implementation of changes, based on the concept of just in time, mapping processes and stratification of the main products of the company through the application of the pulled production system, brought significant gains, with improved customer service And stock reduction.
\end{abstract}

Keywords: Lean manufacturing. Just In Time. Production pulled.

\section{Implantação do sistema de produção puxada em uma empresa de fabricação de tintas e vernizes}

\section{RESUMO}

Existem inúmeras empresas que buscam implantar a filosofia de gestão japonesa, conhecida por lean manufacturing, e seus princípios, visando atingir melhores resultados a partir da redução dos desperdícios. Em que empresa deve mapear todos os seus processos, identificando e eliminando etapas que não agregam valor ao cliente, tornando-se o grande foco. Um dos principais desperdícios combatidos é o estoque desnecessário, que acaba gerando grandes prejuízos, pois implica em custos de manutenção e armazenamento. Assim como risco de perdas por deterioração ou por itens ficarem obsoletos e, ainda assim, os estoques não garantem um bom atendimento ao cliente. A metodologia utilizada foi o levantamento bibliográfico, aplicação de questionário, entrevista, observação direta e coleta de dados através de visitas técnicas, desenvolvido sobre forma de estudo de caso, além da análise dos resultados. Neste estudo, os resultados apontaram que a implantação de mudanças, apoiadas no conceito do just in time, mapeamento dos processos e estratificação dos principais produtos da empresa através da aplicação do sistema de produção puxado, trouxe ganhos significativos, com a melhoria do atendimento ao cliente e redução do estoque.

Palavra-Chaves: Lean manufacturing. Just In Time. Produção puxada. 


\section{INTRODUÇÃO}

O atual nível competitivo mundial tem feito empresas dos mais variados segmentos buscarem aumentar sua competitividade utilizando estratégias que valorizem atributos como custos e qualidade [1].

Isso faz com que as empresas industriais que utilizam a abordagem de produção enxuta gozem, em geral, de uma vantagem competitiva sobre as que utilizam abordagens tradicionais, conforme tem sido percebido pela indústria e também pela academia, não só nos países desenvolvidos, coliHo também nos emergentes [2].

$\mathrm{O}$ estudo sobre o JIT e seus impactos trazem valiosas contribuições para as empresas que buscam redução Ibe desperdícios em seus processos e para isto recorrem a implantação da filosofia japonesa - Lean Manufacturin, que sendo bem conduzida, tende a apresentar resultados eficazes.

O desafio das empresas é de atender ao cliente, cada vez mais exigente, que busca por produtos de qualidade e a um custo baixo.

Diante disto, muitas empresas tem adotado o conceito de JIT que de acordo com [3], em linhas gerais, quer dizer produzir as unidades necessárias nas quantidades necessárias e no tempo necessário.

Na visão do JIT, sua preocupação maior é aumentar continuamente a qualidade dos processos de produção, utilizando como base a redução drástica dos estoques, que podem ter efeitos desastrosos nas finanças de uma empresa, além de ocultar as falhas no processo produtivo que deles se servem para não provocar interrupções nas linhas de produção [3].

Segundo [4], uma das grandes vantagens de se adotar o JIT é a de redução nos níveis de estoque, sem comprometer o atendimento ao cliente, já que se sabe que ter estoque é considerado um desperdício de acordo com:

A visão que se tem do estoque é de um desperdício, porque o estoque consome recursos. De maneira direta, ele eleva os custos, porque o processo destina materiais, capacidade e tempo para gerar produtos que não dão retorno imediato na forma de vendas. Também de forma indireta, ele eleva os custos, quando se destina espaços para armazéns - e tempo de trabalhadores e de computadores para acompanhar os níveis de estoque.

Os ganhos de redução de estoque podem ser atrativos, pois confirme cita [5], custos de manter estoque estão associados a todos os custos necessários para manter certa quantidade de mercadorias por um período. São geralmente definidos em termos monetários por unidade, por período. Os custos de manter estoque incluem componentes como custos de armazenagem, custo de seguro, custo de deterioração e obsolência e custo de oportunidade de empregar dinheiro em estoque (que poderia ser empregado em outros investimentos de igual risco fora da empresa) e custo de furto.

Segundo [4], vale a pena lembrar que o estoque esconde os problemas criados pela má qualidade, pelos tempos de espera muito longos e pelos projetos defeituosos. $\mathrm{O}$ uso de estoques como uma proteção, podem mascarar muitos problemas em um processo. Em adição aos defeitos de qualidade, ele ajuda a suportar os grandes tempos de espera nos pedidos ou os inconvenientes das programações de entrega pouco confiáveis. Fica claro que a produção pode continuar a apoiar-se nos níveis de estoque até que as entregas cheguem. Uma das principais diferenças do JIT é o sistema de puxar a produção ao longo do processo produtivo em função da demanda. Nesse sistema, o material somente é processado em uma operação se ele é requerido pela operação subsequente do processo. Os sistemas tradicionais empurram a produção, desde a compra de matériasprimas e componentes até os estoques de produtos acabados, com base em previsões de vendas [6].

Diante disto, motivada por este potencial de ganhos, a empresa objeto de estudo optou por adotar a filosofia Lean Manufacturing e este trabalho tem por objetivo verificar o seu impacto no que diz respeito ao atendimento ao cliente e alterações nos níveis de estoque.

O objetivo geral da pesquisa é demostrar o impacto da implantação do sistema puxado de produção nos níveis de estoque e no atendimento aos pedidos dos clientes.

Deste modo, a pesquisa tem como questão fundamental: De que forma o Sistema Puxado de produção contribui para a reduçao de estoque e no nível de atendimento ao cliente?

\section{II.REVISÃO BIBLIOGRÁFICA II.1 PRODUÇÃO ENXUTA (LEAN MANUFACTURING)}

A manufatura enxuta refere-se a um novo processo de produção que cobre a empresa toda, englobando todos os aspectos das operações industriais (desenvolvimento de produtos, manufatura, organização e recursos humanos, apoio ao cliente) e incluindo as redes de consumidores e fornecedores. Esse novo processo de produção é governado por um conjunto sistematizado de princípios métodos e práticas [4].

De acordo com [7], o pensamento enxuto pode ser resumido em cinco princípios: determinar precisamente o valor por produto específico, identificar o fluxo de valor para cada produto, fazer o valor fluir sem interrupções, deixar que o cliente puxe valor do produto e buscar a perfeição.

De acordo com [7], o ponto essencial para o pensamento enxuto é o valor. $\mathrm{O}$ valor só pode ser definido pelo cliente final. $\mathrm{E}$ só é significativo quando expresso em termos de um produto específico (um bem ou um serviço e, muitas vezes, ambos simultaneamente) que atenda às necessidades do cliente a um preço específico em um momento específico.

A identificação do fluxo de valor inteiro para cada produto (ou, em alguns casos, para cada família de produtos) é o próximo passo no pensamento enxuto, um passo que as empresas raramente tentam dar, mas que quase sempre expõe quantidades enormes, e até surpreendentes, de desperdício.

Especificamente, a análise do fluxo de valor quase sempre mostra que ocorrem três tipos de ação ao longo de sua extensão: (1). Muitas etapas certamente criam valor; (2). Muitas outras etapas não criam valor, mas são inevitáveis; (3) descobre-se que muitas etapas adicionais não criam valor e devem ser evitadas imediatamente [7].

Segundo [8], o mapeamento do fluxo de valor é uma ferramenta que utiliza papel e lápis e o ajuda a enxergar e entender o fluxo de material e de informações na medida em que o produto segue o fluxo de valor. O que queremos dizer por mapeamento do fluxo de valor é simples: siga a trilha da produção de um produto, desde o consumidor até o fornecedor, e cuidadosamente desenhe uma representação visual de cada processo no fluxo de material e informação. Então, formule um conjunto de questões chave e desenhe um mapa "estado futuro" de como o valor deveria fluir. 
O primeiro passo, desta ferramenta, é identificar as famílias de itens de acordo com semelhanças de processo, ou seja, produtos que passem por etapas semelhantes de processamento e utilizam equipamentos comuns, pela repetitibilidade e não-repetitibilidade ou pelos clientes segmentados em mercados [9], conforme mostrado na Figura 1.

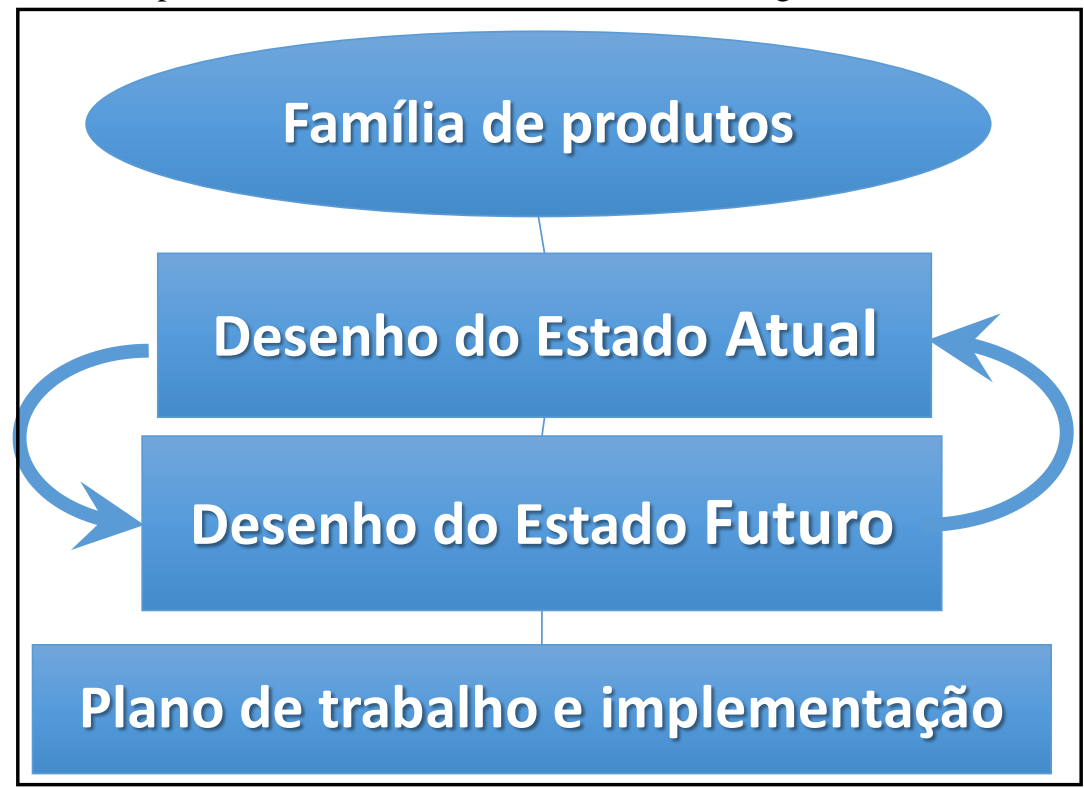

Figura 1: Etapas iniciais do Mapeamento do Fluxo de Valor.

Fonte: Adaptado de [8].

O próximo passo do mapeamento é desenhar os processos básicos de produção. Para indicar um processo usamos uma caixa de processo. A regra geral para manusear o mapa de porta-a-porta é que uma caixa de processo indica um processo no qual o material está fluindo [8], conforme mostrado na figura 2.
De acordo com [8], são utilizados um conjunto de símbolos, ou "ícones", para representar os processos e os fluxos. Você mesmo pode desenvolver seus próprios ícones adicionais, mas mantenha-os consistentes dentro de sua empresa de modo que todos saibam como desenhar e entender os mapas que você necessita para instituir a produção enxuta.

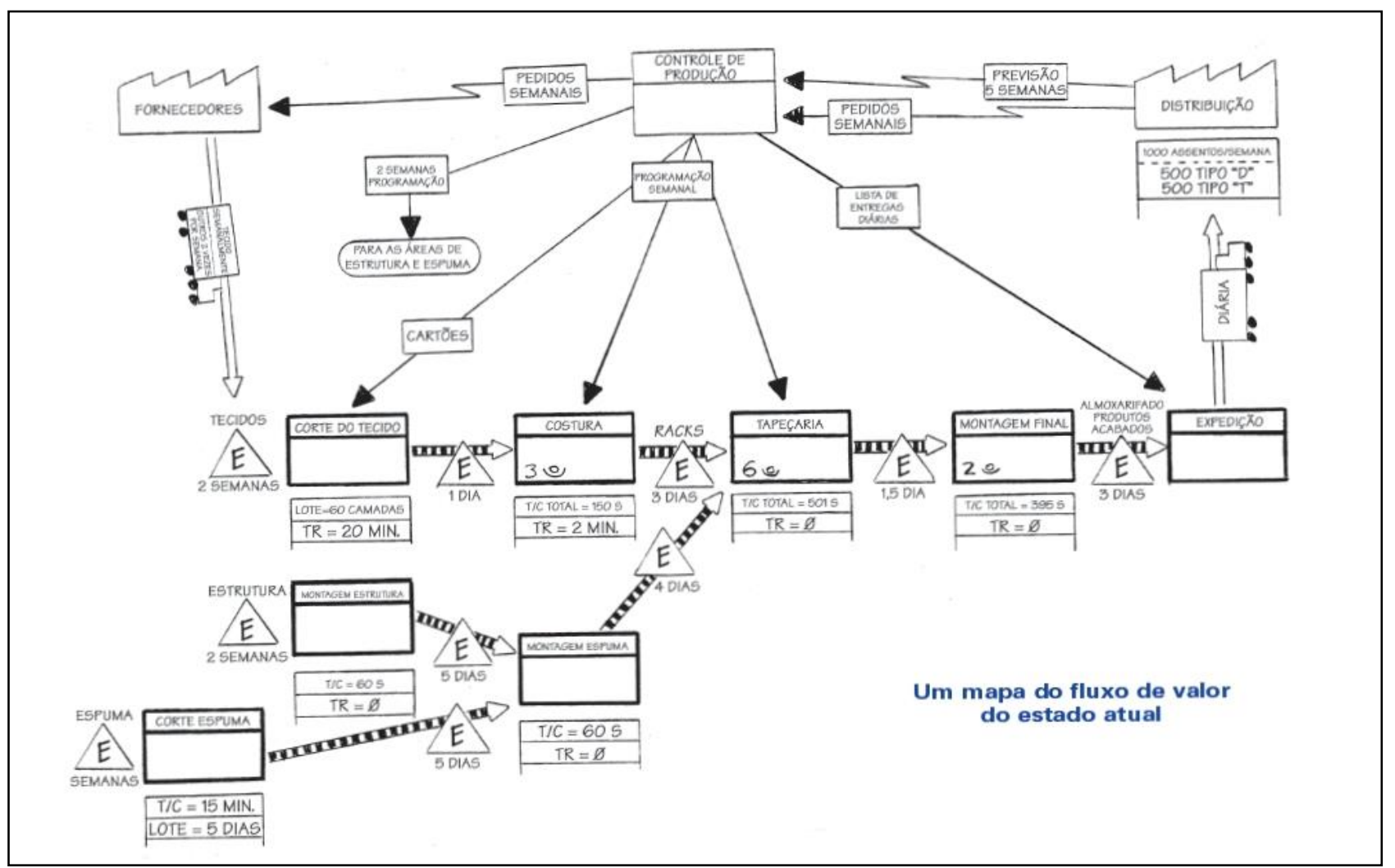

Figura 2: Mapa de Fluxo de valor.

FONTE: [8]. 


\section{II.1.4 PUXAR}

A lógica do sistema puxado é simples: a comunicação no JIT começa ou com a última estação de trabalho na linha de produção ou com o cliente - e depois trabalha para trás por meio do sistema (...) não existe produção em excesso porque os únicos produtos e quantidades produzidos são aqueles especificados pelo kanban [4].

Segundo [7], você pode deixar que o cliente puxe o produto de você, quando necessário em vez de empurrar os produtos, muitas vezes indesejados, para o cliente. Além disso, as demandas dos clientes tornam-se muito mais estáveis quando eles sabem que podem conseguir o que querem imediatamente e quando os produtores interrompem as campanhas periódicas de descontos destinadas a vender mercadorias que já estão prontas e que ninguém quer. Por mais que tenha bons resultados, no entanto [10], atenta que criar uma produção puxada nivelada em uma operação de qualquer complexidade não é simples. Mesmo na Toyota, fora necessários 20 anos de trabalho duros e experimentos, entre 1953 e 1973, para estabelecer o sistema por toda a empresa.

\section{II.2 MODELOS DE PRODUÇÃO: EMPURRADA E PUXADA}

Um sistema de controle da produção eficaz e eficiente deve ser capaz de produzir a quantidade certa, no tempo certo e a um custo competitivo. Estes sistemas são, geralmente, divididos em sistemas empurrado e puxado apesar de não haver um consenso sobre a definição destes termos na literatura [11].

De acordo com [12], a figura 5 ilustra as diferenças entre as abordagens tradicional e JIT. Embora ambas visem à alta eficiência da produção, elas tomam caminhos diversos para conseguir isso. A abordagem tradicional busca a eficiência protegendo cada parte da produção de possíveis distúrbios. Longas corridas ininterruptas de produção constituem o estado ideal.

A abordagem just in time em uma visão oposta. A exposição do sistema aos problemas, pode tanto torná-los mais evidentes, como mudar a "estrutura motivacional" de todo o sistema, em direção à solução dos problemas. O just in time vê os estoques como um "manto negro" que recai sobre o sistema de produção, evitando que os problemas sejam descobertos.

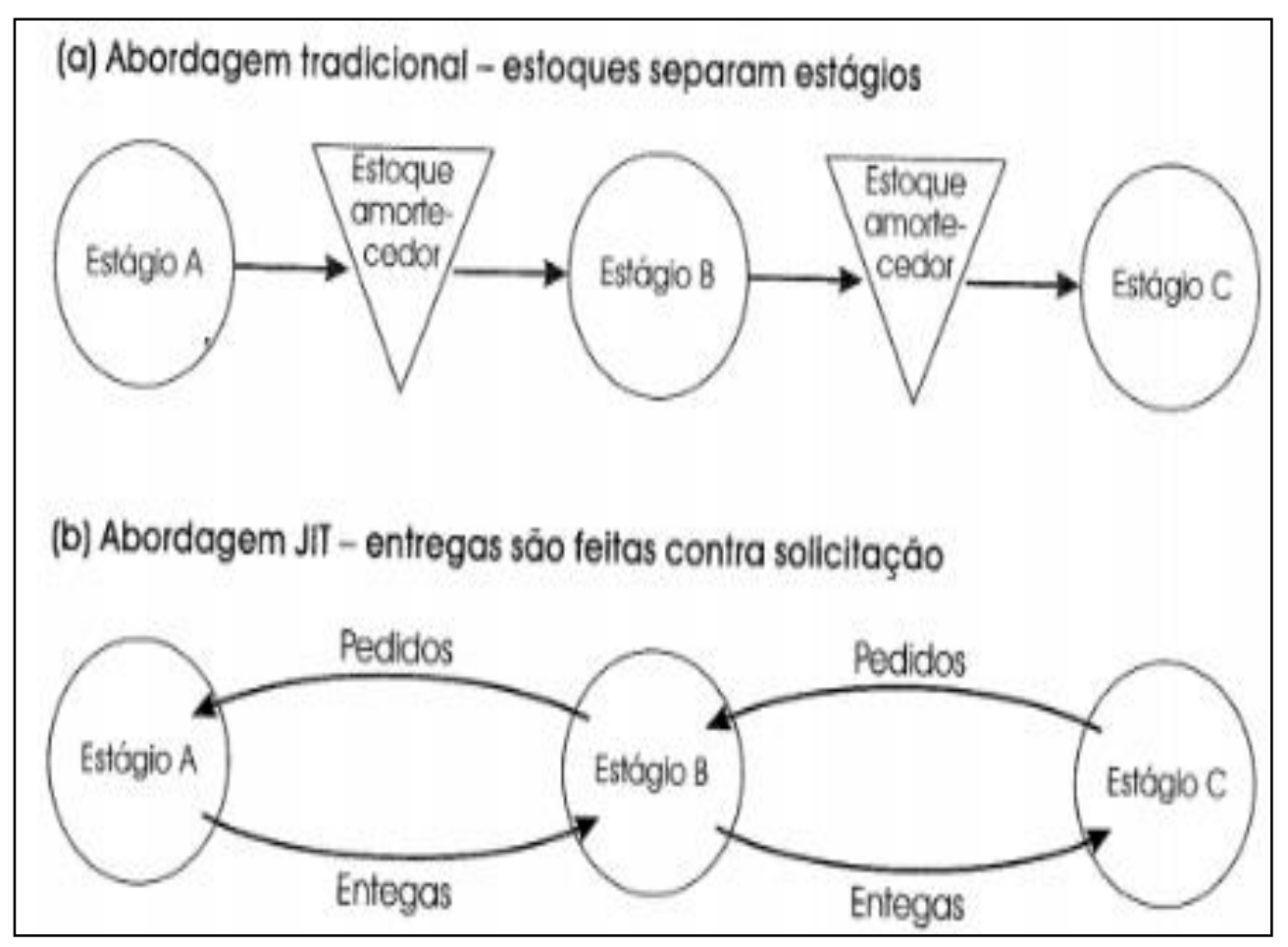

Figura 3: Fluxo (a) tradicional e (b) JIT entre estágios.

Fonte: [12].

\section{II.2.1 PRODUÇÃO EMPURRADA}

Esse é o sistema clássico, comumente conhecido como método de empurrar estoque, push. O fluxo de material é "empurrado" ao longo do processo pela fábrica até a distribuição, para suprir clientes. Esse sistema descontínuo começa com a previsão de vendas que é a base para os programas de produção, os quais são convertidos para os planos de compras [5].

As operações tradicionais da manufatura são sistemas do tipo "empurrado". São baseados na ideia de que é melhor antecipar as necessidades futuras de produção e preparar-se para elas. Os sistemas tradicionais produzem antecipadamente de forma a ter produtos no lugar quando a demanda ocorra. Os produtos são empurrados por meio do sistema e são estocados em antecipação à demanda, o que resulta frequentemente em superprodução porque demanda antecipada pode não se materializar [4].

$\mathrm{O}$ método de previsão geralmente assume que as mesmas causas que estiveram presentes no passado, configurando a demanda, continuarão presentes no futuro. Isso quer dizer que o comportamento do passado é a base para se interferir sobre o comportamento do futuro. É por isso que alguns dizem jocosamente que as previsões são excelentes para se prever o passado e nos enganar acerca do futuro. 
Os métodos não conduzem a resultados perfeitos, e a chance de erro é tanto maior quanto mais nos aprofundamos no futuro, ou seja, quanto maior seja nosso horizonte de previsão. Isso acontece porque os fatores aleatórios, que nenhuma previsão consegue captar, passam a exercer mais e mais influência [4].

Os processos de produção industrial tradicionais são empurrados. Isto significa que cada elo da cadeia de suprimentos, após ter realizado sua atividade de agregação de valor, remete o resultado do seu trabalho para o próximo elo da cadeia a jusante, independentemente de ter havido solicitação nesse sentido. Este tipo de organização produtiva gera estoques de produtos em processo sempre que há desbalanceamento de capacidade produtiva ou algum imprevisto que exija a paralisação das atividades em algum ponto.

Outro inconveniente é que os diversos envolvidos não conseguem saber se o resultado do seu trabalho está sendo aproveita do mais adiante e em que ritmo isto está ocorrendo [13].

No modelo de produção tradicional, em que se trabalha com previsão de demanda, há problemas como citado por [12], em que os pedidos de venda, normalmente, representam um

\section{II.2.2 PRODUÇÃO PUXADA (JUST IN TIME)}

Na última década, o conceito de produção enxuta passou a fazer parte do vocabulário dos gestores das maiores e mais importantes empresas do mundo.

A manufatura enxuta ou "lean manufacturing", do idioma inglês, é baseado no Sistema Toyota de Produção, surgido no Japão após a Segunda Guerra Mundial.

Sistema este criado, como uma alternativa ao sistema de produção em massa, desenvolvido pelas montadoras de carros norte americanas, representadas principalmente pela Ford.

De acordo com [14] os sete tipos de desperdícios identificados por Shigeo Shingo, no Sistema Toyota de Produção, foram: - Perda por superprodução; - Perda por fabricação de produtos defeituosos; - Perda por estoque; - Perda no próprio processamento; - Perda por transporte; - Perda por esperas; Perda por movimentação.

A produção enxuta é um método racional de fabricar produtos pela completa eliminação de elementos desnecessários à produção, com o propósito de reduzir os custos. A ideia básica é produzir os tipos de unidades necessárias, no tempo necessário e na quantidade necessária [15].

A eliminação dos problemas do processo (redução de desperdícios), normalmente encobertos pelos níveis de estoque, é um pressuposto fundamental para a adoção do sistema JIT. Os sistemas tradicionais de administração da produção tendem a considerar níveis de qualidade, tempos de preparação de máquina, tempos de resposta e frequência de quebras como dados imutáveis do sistema, usando os níveis de estoques para encobri-los [6].

De acordo com [5], no JIT, o produto é solicitado quando necessário, e o material é movimentado para a produção quando e

\section{METODODOLOGIA}

\section{III.1 MATERIAIS}

Os materiais utilizados para a implantação do sistema puxado foram as informações cedidas dos processos produtivos, estoques e níveis de atendimento ao cliente. comprometimento contratual por parte do cliente. Entretanto, dependendo do negócio em que uma empresa esteja, este comprometimento pode não ser tão firme como possa parecer.

Os clientes podem mudar de ideia sobre o que necessitam, mesmo depois de ter colocado seus pedidos. Eles podem requerer uma quantidade maior ou menor de um item específico ou mudar a data necessária para a entrega do material. Em virtude de a flexibilidade e o serviço ao cliente estarem tornando-se fatores competitivos cada vez mais importantes.

Considerando que cada um de centenas de clientes pode solicitar mudanças em seus pedidos, não uma vez, mas várias, depois que o pedido foi colocado fica evidente que a gestão da carteira de pedidos é um processo dinâmico e complexo.

Para [12] ainda reforça os desafios de se operar com o modelo tradicional de produção empurrada, citando que qualquer que seja o grau de sofisticação do processo de previsão numa empresa, é sempre difícil utilizar daods históricos para prever futuras tendências, ciclos ou sazonalidades. Dirigir uma empresa que utiliza previsões baseadas no passado pode ser comparado a dirigir um carro olhando apenas para o espelho retrovisor.

onde é necessário (...) O planejamento é agora realizado em direção para trás e puxado pelo cliente e não realizado em direção para a frente e empurrado para o estoque. à medida que:

JIT é uma atividade de valor agregado para a organização

- Identifica e ataca os problemas fundamentais e gargalos;

- Elimina perda e desperdícios;

- Elimina processos complexos;

- Implementa sistemas e procedimentos.

O princípio de funcionamento de um modelo de produção puxada é citado como exemplo por [3], como num supermercado são os clientes que, com suas retiradas de produtos das gôndolas, determinam o momento de reposição dos produtos.

Essa reposição não podia ocorrer antes por várias razões: o produto pode ser perecível e seu prazo de validade vencer antes de ser adquirido; o espaço da gôndola é pequeno, cabendo apenas pequena quantidade do produto; não é possível aumentar o tamanho da gôndola por causa do espaço disponível no supermercado e do custo do espaço.

Portanto, tudo deveria acontecer a partir do momento em que o consumidor retirasse o produto da gôndola. Ou seja, era o consumidor que puxava as atividades de todas as pessoas no supermercado. A produção enxuta lança mão das seguintes ferramentas: Kanban para acompanhar o andamento da produção; Just-in-time para manter a produção no tempo exato; Nivelamento da produção para adaptação às variações da demanda [3].

\section{III.1.1 CARACTERÍSTICAS DA EMPRESA}

A empresa foi fundada pelo grupo argentino Bunge \& Born em 1954, ano em que a empresa, como o País, buscava a consolidação de sua produção para abastecer o emergente mercado interno. Após 41 anos, com a consolidação do Mercosul, a Tintas Coral ampliou os seus horizontes ao compor com a Bunge Paints, uma divisão formada também pelas empresas Alba (Argentina), Inca (Uruguai) e Pinturas Coral (Bolívia). No Brasil, A empresa 
possui duas unidades de negócio de Tintas Decorativas, uma localizada em Mauá-SP e outra em Recife-PE, local do desenvolvimento desta dissertação de mestrado. A unidade de Recife, mostrada na Figura 15, tem uma capacidade produtiva de mais de 60 milhões de litros por ano distribuídos entre massas, texturas e tintas, produzindo uma grande variedade de produtos, cerca de 340 diferentes itens [16].

\section{III.2 MÉTODOS}

O trabalho se caracteriza como um estudo dos resultados da migração de um modelo de produção tradicional empurrado para um modelo de produção puxado em uma indústria de tintas e vernizes, cujo escopo engloba uma família de produtos específica, de maior retorno para a companhia e tem o intuito de comprovar os ganhos de se operar neste modelo.

A pesquisa tem natureza qualitativa e quantitativa, na medida em que estabelece relações entre os modelos aplicados na prática, voltados a filosofia lean manufacturing e os resultados gerados medidos quantitativamente como níveis de estoque e atendimento ao cliente. Em relação à finalidade da pesquisa, pode- se dizer que, o estudo se caracteriza como descritivo, por buscar descrever a correlação entre o novo modo de operação, seus procedimentos e níveis de estoque com o atendimento ao cliente e os novos resultados alcançados. A pesquisa foi literária, documental e de campo por meio de coleta de dados e observação direta durante trabalho no campo, neste caso a indústria de tintas.

Os dados apresentados nesta pesquisa e que foram utilizadas como fonte de informação importantes neste estudo foram coletadas in loco pela autora durante desenvolvimento deste trabalho através de medições diárias do estoque, relatório mensal de atendimento ao faturamento do pedido do cliente e procedimentos operacionais de programação das OSs produção na fábrica.

a) Para as pesquisas bibliográficas foram utilizadas materiais publicados por autores renomados, que já obtiveram resultados em pesquisas semelhantes, como artigos científicos e livros editorados;

b) $\mathrm{Na}$ pesquisa documental foram analisados os resultados;

c) Os dados foram coletados in loco, durante a implantação do projeto através de relatórios de faturamento e de indicadores de produção e contagens físicas dos itens no estoque.

\section{PROCEDIMENTOS}

\section{MAPA DE FLUXO DE VALOR DO PROCESSO}

Inicialmente foi feito um VSM - Value Stream Mapping deste processo na tentativa de identificar os principais desperdícios. Do mapeamento realizado, foi desenhado o mapa do estado atual da Figura 4.

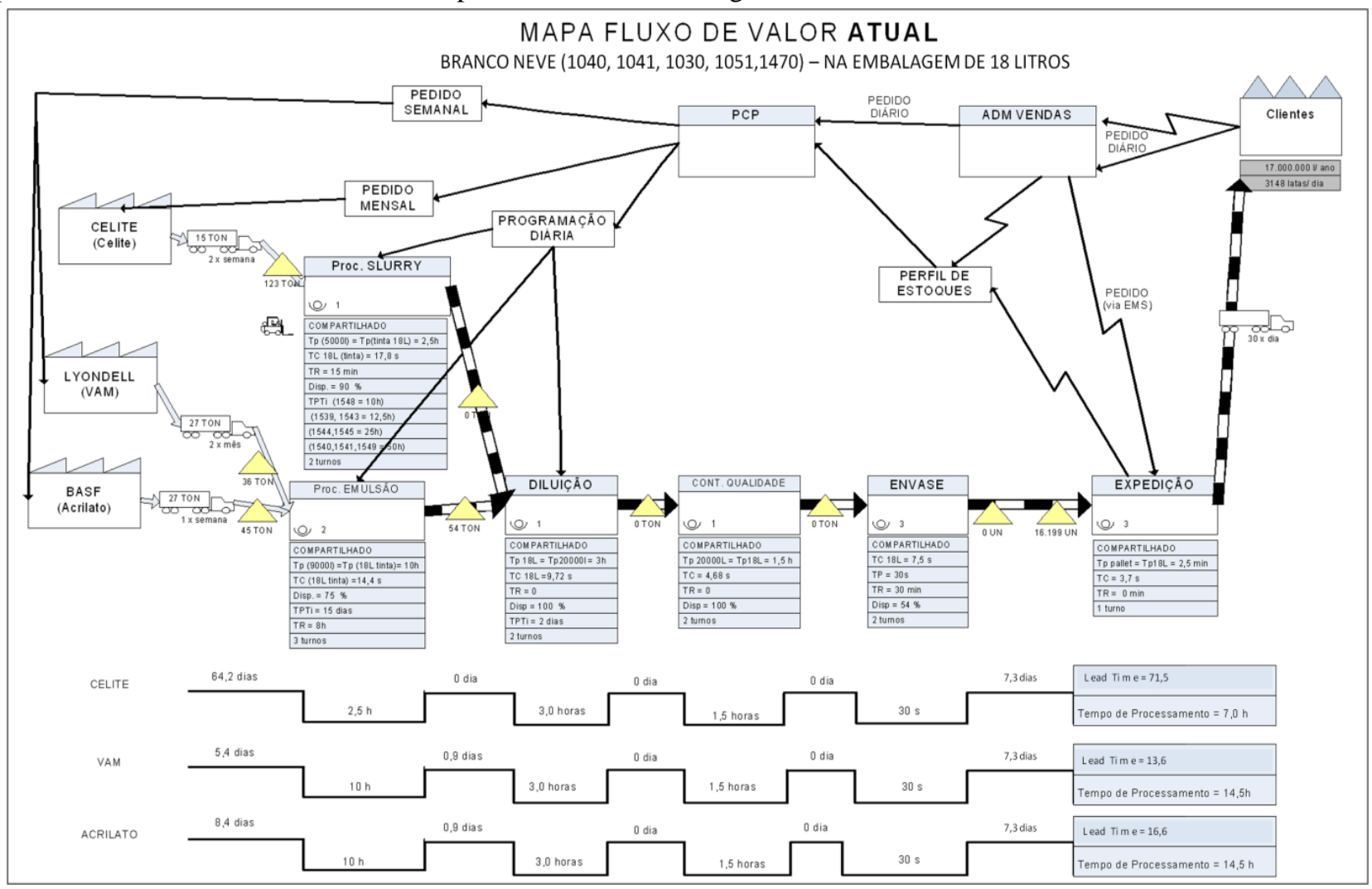

Figura 4: VSM Estado Atual.

Foram eleitas três principais matérias-primas para se realizar o mapeamento até o cliente e, de imediato, foi possível identificar desperdícios ao longo do processo que tem um lead time que chega a 71 dias, diante de um tempo de processo de 7 horas apenas. Ou seja, a grande maioria do lead time está no estoque, tanto de matéria-prima, quanto de produtos intermediários e produto acabado.

Então, foi proposto um VSM do Estado Futuro, visto na Figura 5, visando a redução dos desperdícios, alcançados através da implantação de algumas ações. 


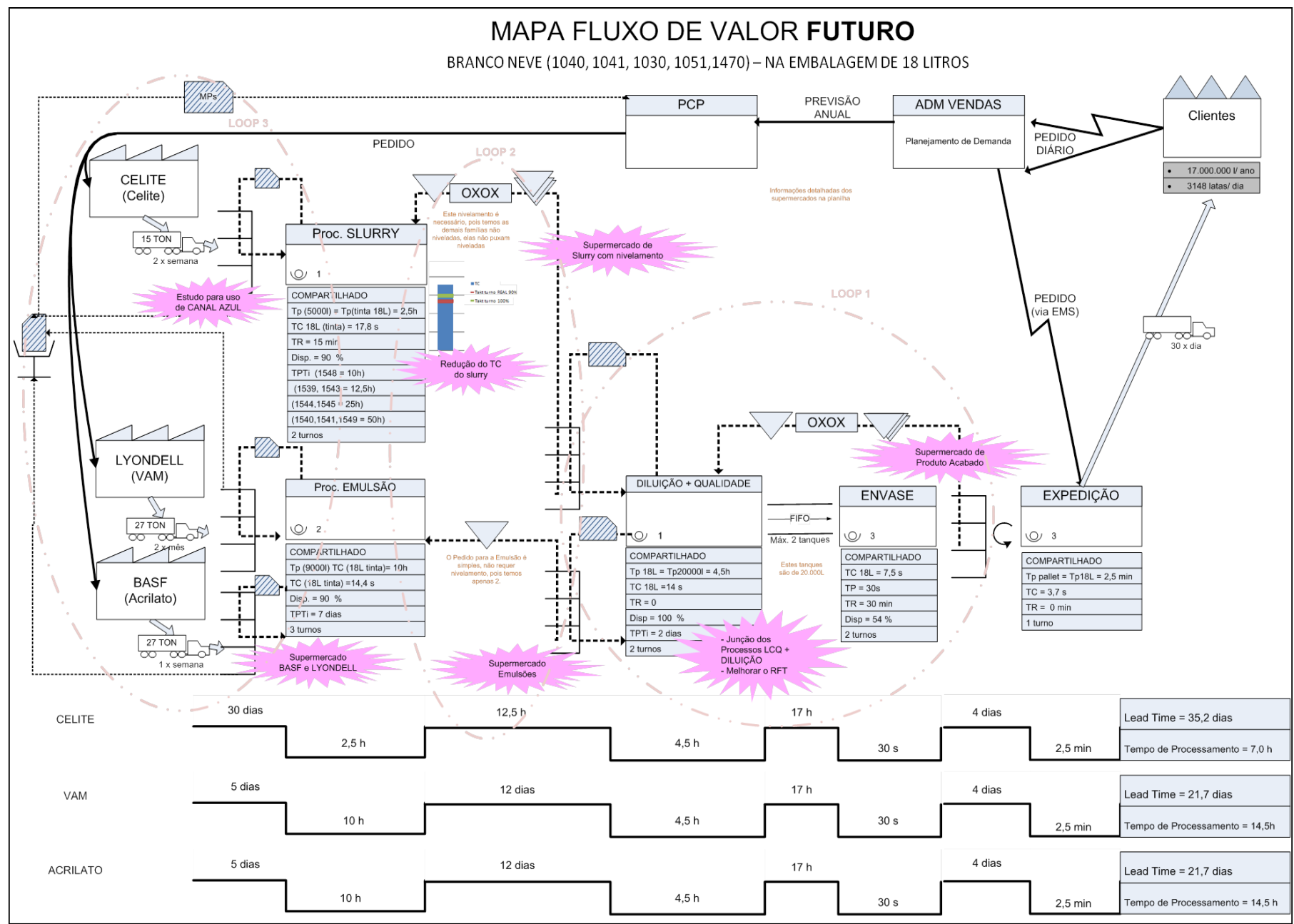

Figura 5: VSM Estado Futuro.

As ações propostas preveem a implantação de supermercados em várias etapas do processo, dentre eles o supermercado de produto acabado que é o foco de estudo deste trabalho, onde a meta é reduzir em $45 \%$ os dias de estoque destes itens, de 7,3 dias para 4,0 dias, sem comprometer o atendimento ao cliente, medido pelo OTIF que representa se o cliente recebeu o pedido completo e no prazo correto. Este indicador atual é de $94 \%$ para estes itens.

Para a implantação do supermercado de produto acabado, foram levantadas informações sobre a demanda média destes itens e sua variação.

Tabela 1: Estoque Total.

\begin{tabular}{c|c|c|c|c|c|c|c|c}
\hline Itens & \multicolumn{2}{|c|}{$\begin{array}{c}\text { Estoque de } \\
\text { ciclo }\end{array}$} & \multicolumn{2}{c|}{$\begin{array}{c}\text { Estoque } \\
\text { pulmão }\end{array}$} & \multicolumn{2}{c|}{$\begin{array}{c}\text { Estoque de } \\
\text { segurança }\end{array}$} & \multicolumn{2}{c}{$\begin{array}{c}\text { Estoque } \\
\text { máximo total }\end{array}$} \\
\hline & Litro & Dias & Litro & $\begin{array}{c}\text { Di } \\
\text { as }\end{array}$ & Litro & $\begin{array}{c}\text { Di } \\
\text { as }\end{array}$ & Litro & $\begin{array}{c}\text { Dia } \\
\text { s }\end{array}$ \\
\hline 1030 & 32.756 & 3,1 & 26.442 & 2,5 & 21.259 & 2,0 & 80.457 & 7,6 \\
\hline 1040 & 33.499 & 4,2 & 18.947 & 2,4 & 15.882 & 2,0 & 68.328 & 8,6 \\
\hline 1041 & 34.179 & 3,9 & 20.559 & 2,3 & 17.724 & 2,0 & 72.462 & 8,2 \\
\hline & 34.450 & 11,9 & 6.427 & 2,2 & 5.780 & 2,0 & 46.657 & $\begin{array}{c}16, \\
1\end{array}$ \\
\hline 1051 & & & & & & & & \\
\hline & 39.020 & 5,3 & 15.395 & 2,1 & 14.630 & 2,0 & 69.045 & 9,4 \\
\hline
\end{tabular}

Em condições perfeitas, sem nenhuma variação tanto de ressuprimento quanto da própria demanda, o esperado é que o nível de estoque varie entre as linha verde e vermelha dos gráficos, ou seja, apenas o estoque de ciclo seja consumido e em seguida reabastecido. No entanto, como também é possível observar no histórico que há grande variação da demanda, em algum momento o nível pode ser inferior a linha vermelha, podendo vir a consumir parte ou todo dos estoques de segurança e pulmão.

$\mathrm{O}$ primeiro passo foi contar todo o estoque e garantir que atingissem os níveis dimensionados para cada item no cálculo e então identificar cada pallet com 01 cartão. Então, o sistema estava configurado para operar no modo de produção puxada, no qual o 
PCP não mais programaria a produção destes itens a partir de previsão, e sim após haver a 'puxada' do cliente, ou seja, assim que um pallet de produto fossem expedido, um cartão deveria ser retirado do pallet e retornar ao quadro de programação da fábrica.
Este quadro, por sua vez, ficava exposto na primeira etapa de produção - diluição - garantindo que assim que a quantidade de cartões atingisse o ponto de pedido - referente um lote de produção, o item deveria ser fabricado, o que na prática obedeceria a regra de nivelamento definida.

\section{RESULTADOS}

\subsection{IMPACTO DA IMPLANTAÇÃO DO SISTEMA PUXADO}

Após a implantação da sistema de produção puxado, os níveis de estoque dos itens 1030, 1040, 1041, 1051 e 1470 apresentaram redução total de $15 \%$, saíram de um estoque total de 333.329 litros para 249.997 litros conforme mostrado no gráfico da Figura 6.

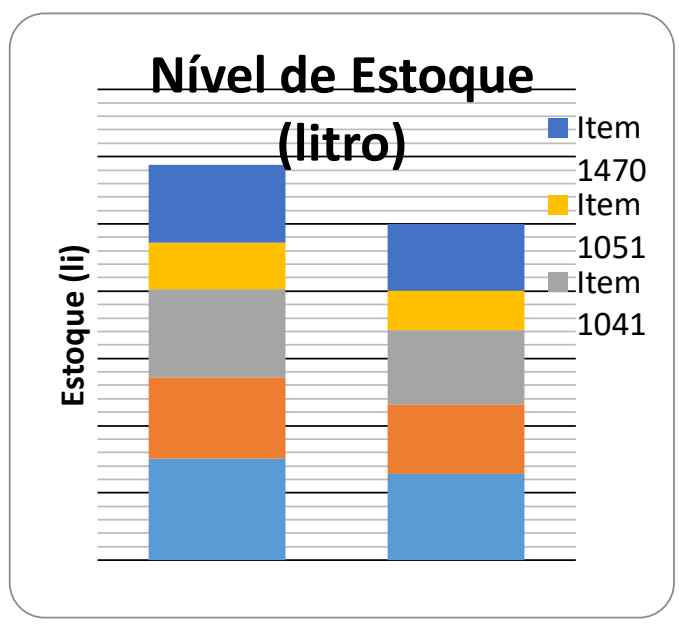

Figura 63: Redução do estoque total dos itens.

Como esta implantação serviu de piloto para os mais de 300 diferentes itens da empresa, no decorrer da implantação, optouse por não atingir a meta inicial de $45 \%$ de redução de estoque, preferiu-se dimensionar estoques pulmão e de segurança robustos o suficiente para suportar picos de demanda e paradas na linha de produção, respectivamente, de forma a não comprometer os pedidos.
Ainda assim, observa-se uma redução significativa nos níveis de estoque $-15 \%$ e garantindo um melhor atendimento aos pedidos do cliente, exposto no gráfico $\mathrm{F}$ abaixo, no qual pode-se ver os resultados do indicador OTIF, monitorando pela Logística e pela área comercial que medem o percentual da quantidade dos itens atendidos e o percentual de pedidos entregue no tempo certo.

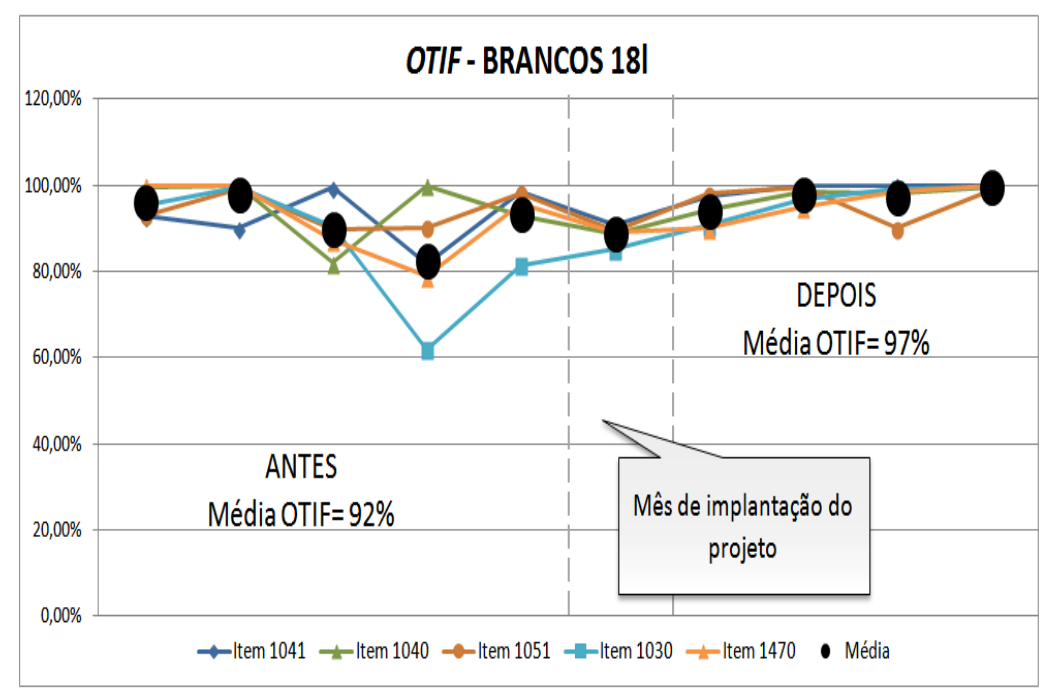

Figura 74: Gráfico de OTIF. Onde, OTIF = OT - On Time (pedido entregue sem atrasos); IN - In Full (pedidos entregues na quantidade desejada, completos).

É possível perceber uma melhora no indicador de atendimento ao cliente, mesmo havendo redução no nível médio de estoque, comprovando a tese de que não é necessário ter altos índices de estoque para um bom atendimento ao cliente, basta ter um sistema de planejamento e programação eficaz, que neste caso é o sistema puxado. Portanto, pudemos comprovar que neste caso prático, a aplicação do sistema puxado em substituição ao sistema tradicional empurrado, levou à redução dos níveis de estoque em $10 \%$, ao mesmo tempo que trouxe uma melhora de $5 \%$ no índice de atendimento aos pedidos dos cliente na quantidade certa e dentro 
do prazo. Além destes resultados alcançados, obteve-se ainda ganhos imensuráveis a partir da implantação do sistema puxado, como o aumento do grau de satisfação do operador que passou a ter maior visão de sua atividade com o atendimento ao cliente, já que não mais precisaria de uma ordem direta do PCP para iniciar a fabricação de um lote, como mostra a figura 44 (A), sem participado de reuniões de planejamento prévias para esta decisão, sendo o operador, apenas um executor.

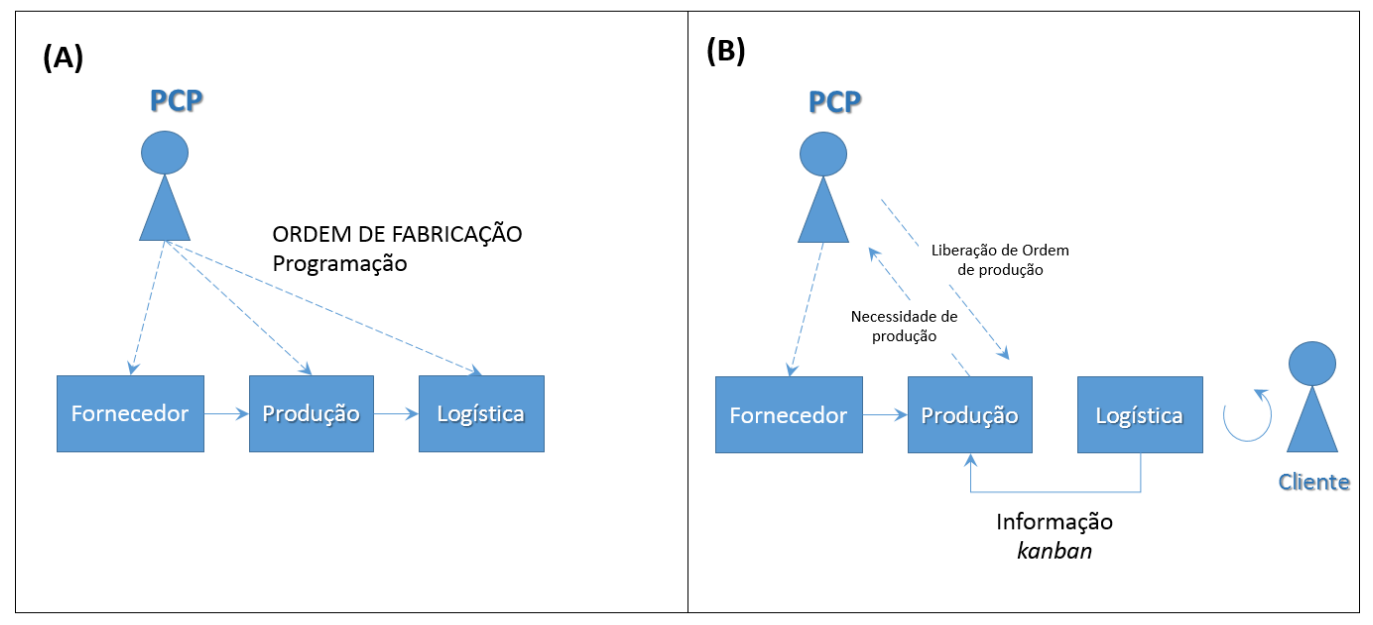

Figura 8: (A) Programação tradicional com PCP programando todas as etapas; (B) Programação nova 'puxada', informação do kanban programando a produção.

Nesta nova configuração, os operadores tanto da logística quanto da produção passam a ser responsáveis pela programação da produção como mostra na figura 44 (B), fazendo a leitura a partir da 'puxada' do cliente que ocasiona a retirada do cartão pelo operador da logística e subsequentemente exige que o operador da produção faça a leitura do quadro kanban, identificando a necessidade de se produzir novo lote, em seguida verificando na régua de nivelamento o momento exato de inciar a fabricação.

No modelo implantado ainda há participação do PCP, pois ele precisa ficar ciente da demanda, emitindo as ordens de produção a partir do alerta do operador. Isto se faz necessário, pois o sistema puxado ainda não foi implantado nas matérias-primas, desta forma, o PCP participa do processo para realizar o pedido de material junto aos fornecedores.

De uma forma geral, as atividades dos operadores passaram a ter maior impacto sobre o negócio e eles puderam sentir a relação de suas rotinas de trabalho com o atendimento aos clientes. Por exemplo, a atividade do operador logístico de retirada do cartão dos pallets expedidos e disponibilização deles no quadro kanban é o determinante para o que a empresa iria produzir, assim como a atividade de observar corretamente os quadros e utilizar a regra de nivelamento para priorizar os itens que deveriam entrar na linha de produção é uma atribuição do operador de produção fundamental para que o produto seja reabastecido no tempo programado e o atendimento ao cliente não seja comprometido.

Estas novas atribuições foram agentes motivadores aos operadores que naturalmente passaram a contribuir com a melhoria dos processos, já que começavam a enxergar o impacto causado por atrasos e falhas, ora nos níveis de estoques que ficavam baixos, pois a informação do nível ideal de estoque passou a ser exposta para todos e por isso facilmente gerido, ora quando observavam filas de ordens de produção aguardando para serem iniciadas.

\section{CONCLUSÃO}

Os resultados obtidos pela implantação do sistema puxado de produção trouxe ganhos de atendimento ao cliente e redução do estoque. Em relação ao sistema tradicional empurrado pode-se constatar que o sistema puxado torna a programação da produção mais confiável e reduz o risco de falha no atendimento ao cliente, pois tem sua ordem de produção expedida pelo PCP apenas quando o cliente realiza o pedido de fato, não dependendo mais de uma previsão de vendas que costuma falhar.

Com a mudança para o sistema puxado, os estoques foram devidamente dimensionados e os atrasos no atendimento aos pedidos dos clientes reduziram. A escolha por este sistema trouxe resultados importantes para a empresa, pois aumentou o nível de atendimento em seus produtos que possuem maior volume de vendas.

Outro ganho com a implantação da filosofia lean manufacturing foi a melhoria na gestão dos processos, pois a informação sobre os níveis ideias de estoque e a necessidade de produção passou a ser exposta nos quadros kanban, permitindo a gestão por todos, inclusive operadores que anteriormente não se envolviam no processo, ficando restritas as informações aos coordenadores e supervisores de produção. Tal mudança, acarretou em maior envolvimento e motivação de todo time operacional.

\section{AGRADECIMENTOS}

Ao Instituto de Tecnologia e Educação Galileo da Amazônia (ITEGAM), ao PPGEP do Instituto de Tecnologia Universidade Federal do Pará (PPGEP-ITEC-UFPA). 


\section{REFERÊNCIAS}

[1] Shimizu, Ullisses Kazumi; Basso, Leonardo Fernando Cruz; Nakamura, Wilson Toshiro. Produção enxuta e desempenho de mercado: uma análise para o setor de máquinas e implementos agrícolas no Brasil. In: Simpósio de Administração da Produção, Logística e Operações Internacionais (SIMPOI), 9. 2006, São Paulo. Anais... São Paulo: FGV-EAESP, 2006.

[2] Stevenson, William J. Administração das operações de produção. 6.ed. Rio de Janeiro: LTC, 2001.

[3] Ballesrtero-Alvarez, Maria Esmeralda. Gestão de Qualidade, Produção e Operações. 2 ed. São Paulo: Editora Atlas S.A. 2012.

[4] Moreira, Daniel Augusto. Administração da Produção e Operações. 2 ed. São Paulo: Cengage Learnig, 2011.

[5] Ching, Hong Yuh. Gestão de Estoques na Cadeia de Logística Integrada - Supply Chain. 4 ed. São Paulo: Editora Atlas, 2010.

[6] Wanke, Peter. Gestão de Estoques na Cadeia de Suprimentos. 3 ed. São Paulo: Editora Atlas, 2011.

[7] Womack, James P; Jones, Daniel T. A mentalidade enxuta nas empresas: elimine o desperdício e crie riqueza. Rio de Janeiro: Elsevier, 2004.

[8] Rother, Mike; Shook, John. Aprendendo a enxergar Mapeando o fluxo de valor para agregar valor e eliminar o desperdício. Massachusetts: Lean Enterprise Institute, 2003.

[9] Rother, M; Shook, J. Learning to see - Value Stream mapping to Add Value and Eliminate Muda. The Lean Enterprise Institute, MA, USA, 1998.

[10] Smalley, Art. Criando o sistema puxado nivelado. Brookline: Lean Enterprise Institute, 2004.

[11] Spearman, M. L.; Woodruff, D. L.; Hopp, W. J.: CONWIP: a pull alternative to Kanban. International Journal of Production Research. V.28, n.5, p. 879-894, 1990.

[12] Slack, Nigel; Chambers, Stuart; Johnston, Robert. Administração da produção; 3 ed. São Paulo: Atlas, 2009.

[13] Peinado, Jurandir. Graeml, Alexandre. Administração da Produção (Operações industriais e de serviços). Curitiba: UnicenP, 2007.

[14] Womack, J.P., \& Jones, D.T. Lean Thinking: Banish Waste and Creat Wealth in Your Corporation. New York,NY: Simom \& Schuster, 1996.

[15] Mondem, Yasushiro. Sistema Toyota de Produção. São Paulo: IMAM, 1984.

[16] Borges, Adriana. Processo de Fabricação de Tintas pela Empresa do Grupo Akzonobel na Unidade de Recife-PE. Monografia, 2009. 